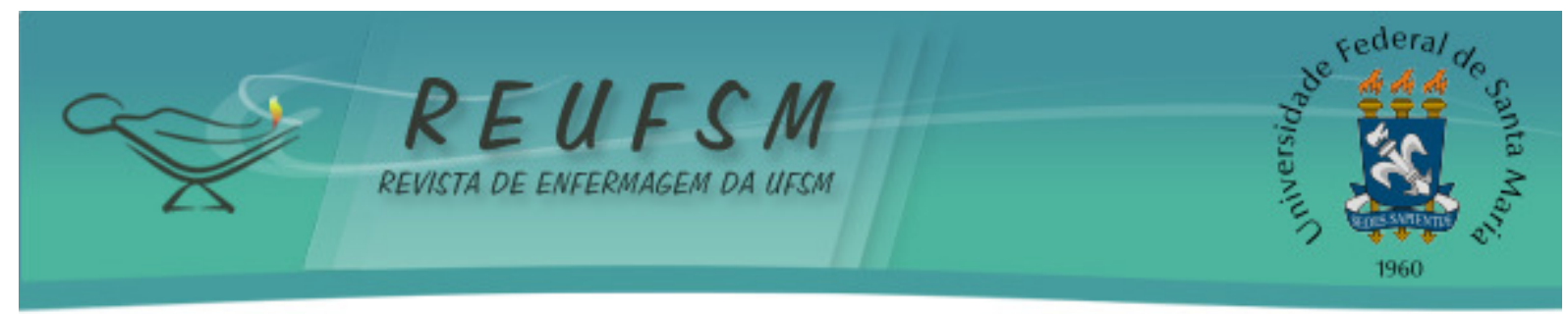

ARTIGO ORIGINAL

\title{
O CONHECIMENTO DOS FAMILIARES SOBRE CUIDADOS À CRIANÇA COM LEUCEMIA LINFOCÍTICA AGUDA NO ISOLAMENTO PROTETOR
}

\author{
FAMILY KNOWLEDGE ON CHILD CARE WITH ACUTE LYMPHOCYTIC LEUKEMIA \\ IN PROTECTIVE ISOLATION
}

\section{EL CONOCIMIENTO DE LA FAMILIA SOBRE LOS CUIDADOS A LOS NIÑOS CON LEUCEMIA LINFOBLÁSTICA AGUDA EN AISLAMIENTO PROTECTOR}

Doi: $10.5902 / 2179769222994$

\author{
Ellen Pessoa Rocha ${ }^{1}$ \\ Arinete Véras Fontes Esteves ${ }^{2}$ \\ Elizabeth Teixeira ${ }^{3}$ \\ Marcos Vinícius Costa Fernandes ${ }^{4}$
}

RESUMO: Objetivo: descrever o conhecimento dos familiares sobre os cuidados à criança com leucemia linfocítica aguda em isolamento protetor. Método: estudo de natureza qualitativa e descritiva, realizado no isolamento do centro de Referência para doenças onco-hematológicas da Região Norte, em Manaus, por meio de entrevista semiestruturada com 11 familiares, entre janeiro e março de 2016. Os dados foram analisados através da Análise Temática. Resultados: nas categorias: "Isolamento Protetor como prevenção de infecção: ainda um bicho de sete cabeças?" e "Cuidados no Isolamento Protetor: é preciso que todos tenham informações"; observou-se que o isolamento possui várias facetas: de proteção, prevenção, separação, que foram vivenciados pelos familiares nesse ambiente cuja rotina é diferenciada para cuidar da criança leucêmica. Conclusão: permeados de dúvidas e ansiedade, os familiares conhecem pouco sobre os cuidados a criança no isolamento; mostraram-se dispostos a aprender e sugerem a construção de um material educativo para facilitar o empoderamento do conteúdo.

DESCRITORES: Relações familiares; Leucemia-linfoma linfoblástico de células precursoras; Isolamento de pacientes; Tecnologia educacional; Saúde da criança.

ABSTRACT: Aim: to describe family members' knowledge about child care with acute lymphocytic leukemia in protective isolation. Method: this was a qualitative and descriptive study, carried out in the isolation of the Reference center for oncohematological diseases of the Northern Region, in Manaus, through a semi-structured interview with 11 relatives, from January to March 2016. Data were analyzed through Thematic Analysis. Results: from the categories: "Protective Isolation as infection prevention: is it still a seven-headed animal?" and "Protective Isolation Care: everyone needs information" it was possible to observe that the isolation has several facets. For

\footnotetext{
1 Enfermeira, Mestre em Enfermagem pela Universidade Federal do Amazonas em associação com a Universidade do Estado do Pará, egressa da Universidade Federal do Amazonas, Professora da Faculdade Maurício de Nassau, Manaus, Amazonas, Brasil. Email: rocha.ellen2011@hotmail.com

2 Enfermeira, Doutora em Ciências, área da Psicologia pela Universidade de São Paulo - Ribeirão Preto. Professora Associada da Escola de Enfermagem de Manaus da Universidade Federal do Amazonas, Manaus, Amazonas, Brasil. Email: arineteveras@bol.com.br

${ }^{3}$ Enfermeira, Pós-Doutorado em Enfermagem pela Universidade Estadual Rio de Janeiro, professora Adjunto da Universidade Estadual do Rio de Janeiro, Diretora do Centro de Educação em Enfermagem Aben Nacional 2016 2019, Rio de Janeiro, Rio de Janeiro, Brasil. Email: etfelipe@hotmail.com

${ }^{4}$ Enfermeiro, Mestrando pela Universidade Federal do Amazonas - UFAM em associação com a Universidade do Estado do Pará - UEPA, professor da Faculdade Estácio de Sá - Campus Manaus, Manaus, Amazonas, Brasil. Email: mvcf_2012@hotmail.com
} 


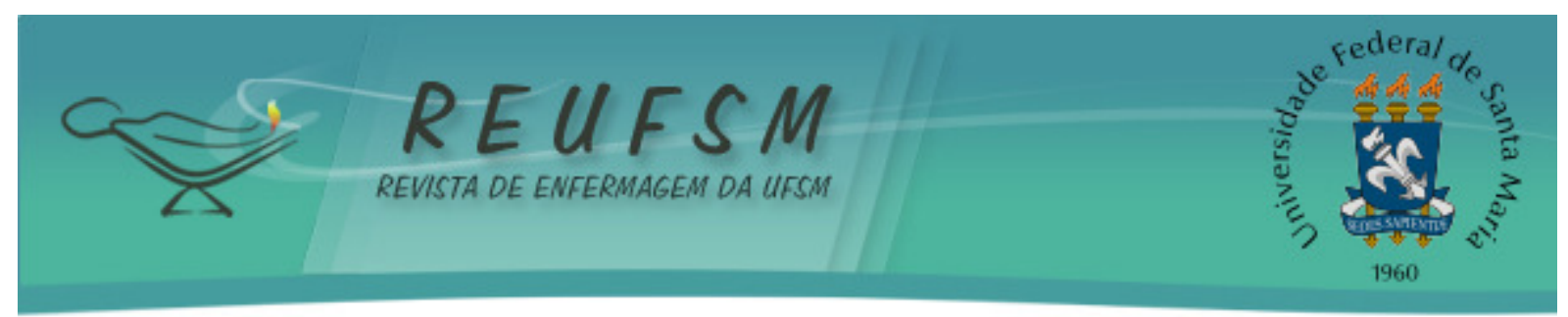

instance, protection, prevention and the separation experienced by the family in this environment (whose routine is differentiated in order to care for the leukemic child). Conclusion: family members know little about child care in isolation and are permeated with doubts and anxiety. They have been willing to learn and suggest the construction of an educational material to facilitate the empowerment of content.

DESCRIPTORS: Family relations; Precursor cell lymphoblastic leukemia-lymphoma; Patient isolation; Educational technology; Child health.

RESUMEN: Objetivo: describir el conocimiento familiar sobre el cuidado a los niños con leucemia linfoblástica aguda en aislamiento protector. Método: estudio descriptivo cualitativo, en un centro de referencia de aislamiento para enfermedades oncohematológicas de la Región Norte, en Manaus, por medio entrevistas semiestructuradas con 11 familiares, entre enero y marzo de 2016. Los datos fueron analizados a través de análisis temático. Resultados: en las categorías: "Aislamiento con blindaje como prevención a la infección: un trabajo complejo" y "Cuidado en el blindaje de aislamiento: todos deben tener información"; se observó que el aislamiento tiene múltiples facetas: protección, prevención, separación que fueron vividas por la familia en un espacio en el cual la rutina es diferenciada para cuidar del niño con leucemia. Conclusión: con muchas dudas y ansiedad, la familia sabe poco sobre la atención de aislamiento, pero quiere aprender y sugiere el desarrollo de un material educativo para facilitar el empoderamiento del contenido.

DESCRIPTORES: Relaciones familiares; Leucemia-linfoma linfoblástico de células precursoras; Aislamiento de pacientes; Tecnología educacional; Salud del ninõ.

\section{INTRODUÇÃO}

O câncer representa mais que uma dor física ou um desconforto, pois envolve significações individuais e coletivas que influenciam nos objetivos da vida da criança, bem como altera a dinâmica da vida familiar com relação ao trabalho, renda, deveres de casa e cuidados com outros filhos. Ocasiona na criança doente alterações dos hábitos de vida, das atividades diárias, da imagem corporal, e traz mudanças transitórias ou definitivas que podem repercutir de forma negativa em seu cotidiano, afetando a todos ao seu redor. ${ }^{1}$

No mundo, a incidência de câncer em crianças de 0 a 15 anos, vem crescendo quando comparada ao câncer em adultos. Cerca de 1\% a 3\% de todos os tipos de câncer na maioria da população mundial ocorre na faixa etária pediátrica. Essa incidência varia entre 30 a 300 casos novos por milhão. No Brasil, a incidência de todos os tipos de câncer nas crianças menor de 16 anos varia entre 1,5\% a 6,5\%, com um risco entre 20 a 250 casos novos por ano por milhão. ${ }^{2}$

Nesse contexto, muitas famílias procuram se ajustar a realidade de uma doença desconhecida como o câncer infantil, causando alterações, desordens e manifestações de sentimento negativos como tristeza, temor e impotência, e produzindo experiências carregadas de medo e esperança advindas do início do tratamento que suscita em idas e vindas ao hospital. ${ }^{3}$

Um dos tipos de câncer infantil mais frequente é a Leucemia Linfocítica Aguda (LLA). A LLA possui uma sintomatologia peculiar que inclui: fadiga, febre, sangramentos secundários a trombocitopenia, dor, hipersensibilidade óssea, linfadenopatias generalizadas como as hepato e esplenomegalias, manifestações do sistema nervoso central, que envolvem as cefaleias, vômitos e paralisia dos nervos faciais, causando dificuldade no diagnóstico, pois pode confundir com outras patologias. ${ }^{4}$

Para tratar a LLA, a quimioterapia é a terapêutica de escolha. A criança precisa 


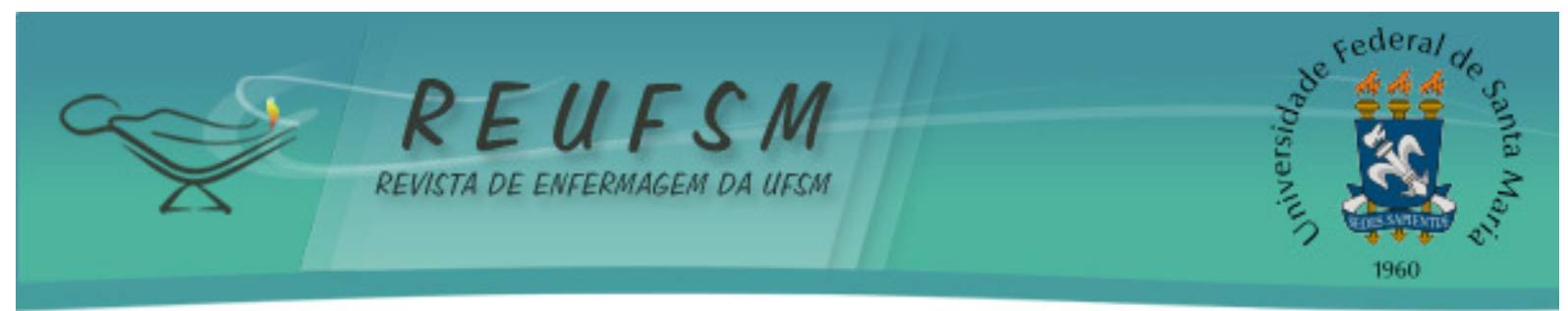

estar hospitalizada para o atendimento de suas possíveis intercorrências de saúde, devido aos efeitos esperados e adversos que podem debilitá-la física e emocionalmente. ${ }^{5}$

Os antineoplásicos prescritos são determinados segundo o protocolo do Grupo Brasileiro de Tratamento de Leucemia na Infância (GBTLI) e o estado clínico da criança. 0 GBTLI é formado por um grupo de pesquisadores que estudam a leucemia e buscam a terapia com melhor sobrevida e menos riscos de toxicidade para a criança. Geralmente, durante o tratamento, o paciente fica imunodeprimido e pode ter comprometimento de suas defesas orgânicas ocasionando anemia, leucopenia e plaquetopenia, expondo-o a infecções oportunistas; nesse contexto, se fazendo necessário o isolamento protetor. ${ }^{6}$

Para adaptar-se a este novo ambiente em que a criança está inserida, o familiar precisa ser informado sobre os cuidados a serem prestados à criança com alterações no sistema imunológico, a fim de entender os motivos e a necessidade da criança em permanecer neste isolamento, longe do convívio de outras crianças internadas. Neste contexto, a educação em saúde é uma forma de orientar e solucionar as dúvidas a respeito do isolamento protetor, pois entende-se que o familiar sem informações pode exercer grande influência sobre o doente e o curso do tratamento a ser realizado. ${ }^{7}$

Apesar dos esforços em agregar a missão de educar à arte do cuidado humanizado, sabe-se que em muitas instituições hospitalares, o cotidiano profissional e o cuidado técnico não abrem espaços para a educação e orientação sobre as necessidades existenciais e a busca por respostas de aspectos vivenciados em ambiente hospitalar pelos familiares cujas crianças estão enfermas. ${ }^{8}$

Como forma de intermediar ações educativas para o cuidado em saúde, a equipe de enfermagem (enfermeiros e técnicos) pode utilizar as tecnologias educacionais, uma espécie de ferramenta que auxilia o processo de ensino-aprendizagem nas instituições de saúde. ${ }^{9}$ Para que essas tecnologias se tornem sensíveis à realidade e ao contexto vivenciado pelos familiares, buscou-se resposta à seguinte questão: qual o conhecimento dos familiares que acompanham crianças com LLA internadas sobre os cuidados em isolamento protetor?

A partir da relevância da temática e considerando que os familiares sejam pessoas chave no cuidado ao paciente com leucemia em tratamento no isolamento protetor, objetivou-se descrever o conhecimento dos familiares sobre os cuidados à criança com leucemia linfocítica aguda em isolamento protetor.

\section{MÉTODO}

Trata-se de um estudo com abordagem qualitativa, de caráter descritivoexploratório, desenvolvido no setor de internação, área de isolamento, de um hospital público que trata de pacientes com doenças onco-hematológicas. A unidade é referência para todos os hospitais da Região Norte, situado na cidade de Manaus no estado do Amazonas. O hospital possui um total de 22 leitos, sendo que há apenas 1 leito de isolamento destinado ao público infantil. A capacidade de lotação conta com leitos extras, que, geralmente, excede 30 internações além do quantitativo normal.

Os participantes da pesquisa foram 11 familiares de crianças com LLA internadas em isolamento protetor. Foram selecionados a partir de uma amostragem intencional que possibilitava decidir propositalmente sobre a seleção dos participantes, pois se teve interesse na opinião e na contribuição da experiência vivida considerada peculiar da população, por conhecer e conviver com a criança que se manteve no isolamento protetor. Os critérios de inclusão para o estudo: pessoas maiores de 18 anos, em adequadas condições físicas e psicológicas para responder as perguntas e aqueles familiares cuja criança não estivesse com alteração grave do quadro clínico no momento da entrevista. 0 


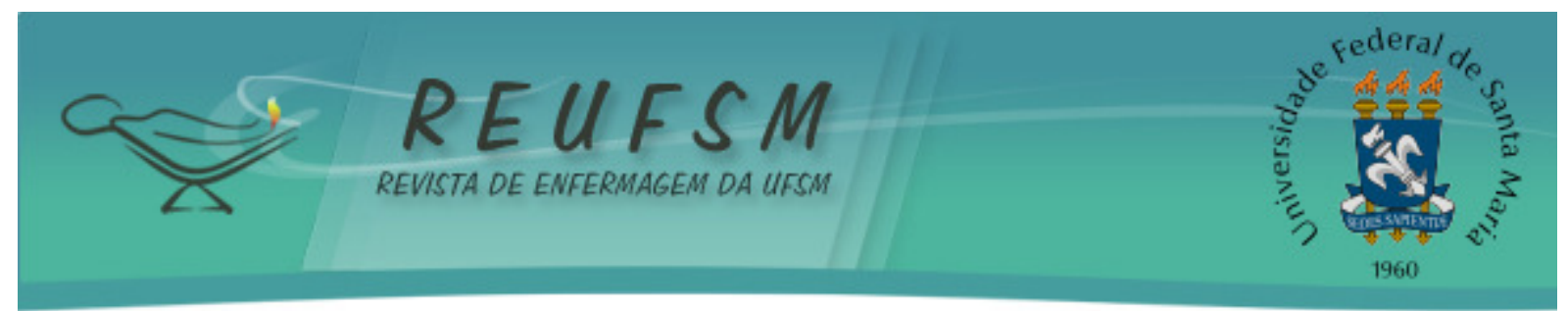

critério de exclusão foi: pessoas de outros países e/ou culturas, pela dificuldade em entender a língua portuguesa.

Nesta etapa, a literatura recomenda no mínimo vinte participantes; contudo, nas amostras não-probabilísticas (intencionais), a definição da quantidade de pessoas é feita a partir da experiência do pesquisador no campo da pesquisa, numa empiria pautada em raciocínios instruídos por conhecimentos teóricos da relação entre o objeto de estudo e o corpus a ser estudado. Portanto, decidiu-se por 11 participantes, a partir do método de saturação teórica. ${ }^{10}$

Todos assinaram o termo de consentimento livre e esclarecido, e apenas um participante utilizou o polegar direito representando sua assinatura e, a partir disso, para resguardar a identidade dos participantes, os familiares foram codificados com a letra "F" de familiar, ordenados na ordem numérica 1-11, segundo a realização das entrevistas.

0 estudo foi elaborado dentro das normas e princípios éticos para pesquisas que envolvem seres humanos, com base na Resolução do Conselho Nacional de Saúde, $n^{0 .}$ 466, de 12 de dezembro de 2012. Foi aprovado pelo Comitê de Ética e Pesquisa da Universidade Federal do Amazonas - UFAM (CAAE 51299815.5.0000.5020).

Para a coleta de dados, que ocorreu de janeiro a março de 2016, utilizou-se a entrevista semiestruturada, guiada por um roteiro previamente elaborado que serviu de orientação para conhecer sobre o conteúdo desejado cujas perguntas constavam: "O senhor (a) sabe que seu filho está no isolamento? Sabe a causa? Quem the deu as informações? Sabe qual a necessidade do isolamento para seu filho (a)? Conhece os cuidados necessários a criança em isolamento? Qual sua opinião em receber um material educativo contendo as informações sobre o isolamento?"

As entrevistas foram realizadas no quarto privativo onde estavam presentes o familiar e a criança hospitalizada. Foram audiogravadas com anuência dos participantes e tiveram duração média de 20 a 30 minutos.

Os dados foram coletados pela própria pesquisadora. Empregou-se a Análise Temática, ${ }^{11}$ que consiste em identificar os núcleos de sentido que compõem um diálogo, cuja presença signifique algo para o objetivo pretendido. Desdobra-se em três etapas: préanálise, exploração do material e tratamento dos resultados obtidos e interpretação. Nesta última etapa, buscou-se os significados nas falas dos entrevistados, para analisar e associar com o referencial teórico. A partir da análise dos dados emergiram duas as categorias: Isolamento Protetor como prevenção de infecção: ainda um bicho de sete cabeças? e Cuidados no Isolamento Protetor: é preciso que todos tenham informações.

\section{RESULTADOS E DISCUSSÃO}

Quanto ao perfil dos 11 familiares (10 mães e um pai), identificou-se que a faixa etária variou entre 20 e 45 anos; um familiar era analfabeto, dois tinham o ensino fundamental incompleto, três o ensino médio incompleto, quatro o ensino médio completo e um o ensino superior. Quanto a atividade profissional, sete estavam desempregados, quatro estavam trabalhando regularmente e se desdobravam para participar ativamente da vida de seus filhos, quando estes encontravam-se internados para o tratamento da LLA.

0 período de acompanhamento e hospitalização das crianças com LLA em tratamento variou entre 26 dias a quatro anos; sendo que a faixa etária das crianças variou de 1 ano e 4 meses a 14 anos, 08 eram do gênero masculino e 03 do feminino.

\section{Isolamento Protetor como prevenção de infecção: ainda um bicho de sete cabeças?}

Ao solicitar que respondessem sobre a causa de a criança estar no isolamento 


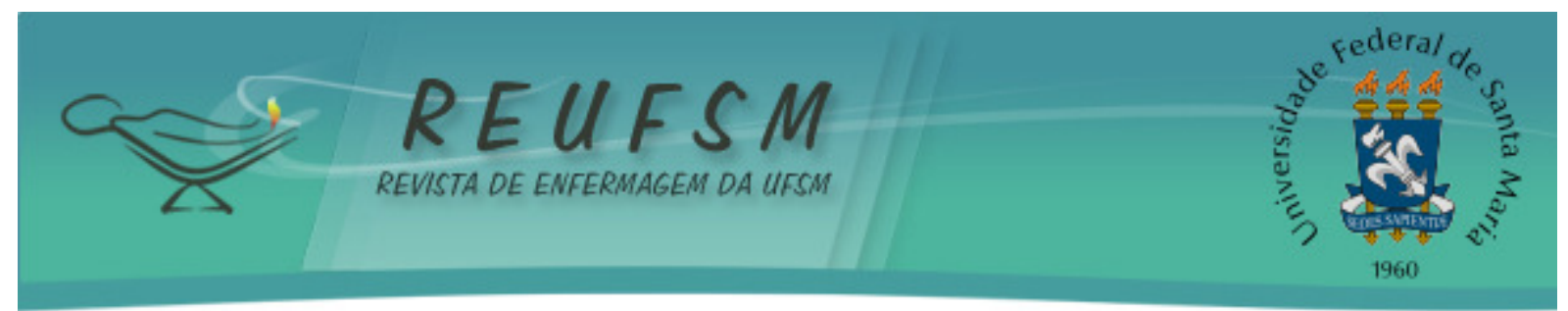

protetor; a intenção foi obter evidências sobre o conhecimento dos familiares a respeito do ambiente (isolamento) como um local diferenciado. Os familiares referiram que o isolamento protetor era um ambiente separado dos demais pacientes internados e durante a transferência, nenhum se mostrou resistente; indicaram os motivos para tal transferência, e a maioria acreditava ser o lugar ideal para as crianças não contraírem outras enfermidades, devido estar com baixa imunidade.

Sobre o motivo que levaram as crianças ao isolamento protetor, assim se expressaram:

[...] sei, mais ou menos. Me falaram que é por causa do braço dele [apontava para uma flebite que a criança tinha no braço esquerdo]. E depois ninguém me falou mais nada. ( $\mathrm{F} 1)$

[...] e quando eu vim pra cá, eu entendi que era pela imunidade baixa para ela não ter a infecção. A doutora me disse isso. (F2)

[...] sei sim. É para evitar de pegar bactéria [...], como ele está com a imunidade muito baixa, ele precisava do isolamento. Mas a doutora me disse que ele já estava com bactéria. (F10)

[...] sim, sei. A causa é a leucemia. A doutora que me deu as informações. (F3)

[...] isso é uma pergunta difícil. Eu não sei dizer por que ele está no isolamento. (F4)

Nota-se que o conhecimento a respeito de doença da criança para alguns pais é limitado; porém a compreensão em aceitar o isolamento é um grande passo para a continuidade do tratamento. No estudo realizado em Maringá com pais de crianças com câncer, foi observado que, se bem orientada, a família exerce um papel fundamental para o curso da doença da criança, demonstrando a importância de informações específicas aos familiares. ${ }^{3}$

Dentre as respostas obtidas dos participantes, revela-se o impacto e o medo de uma das mães a respeito da transferência da criança para o isolamento protetor, apesar de entender que o local seria adequado para prevenção de infecção oportunista:

[...] eu achava que era um bicho de sete cabeças, eu tinha medo por causa do meu filho. Para mim só ia para o isolamento as pessoas que estavam bem graves, até que percebi que era para o bem dele. (F7)

Entende-se que para os familiares, o diagnóstico da doença crônica como a leucemia, traz muitas incertezas quanto ao resultado esperado da terapêutica realizada. No estudo realizado no hospital público da Paraíba com pais de crianças com doenças crônicas, foi observado que a definição do diagnóstico e dos eventos que apoiam o tratamento da doença, são essenciais para que a família possa amenizar a tensão e a ansiedade frente ao desconhecido. Assim, ressalta-se a importância de explicar os fatos que envolvem a transferência para o isolamento protetor. ${ }^{12}$

0 isolamento protetor é entendido como um lugar com função de proteção; os pais acreditavam que pelo fato das crianças ficarem isoladas devido a aplasia medular, também 


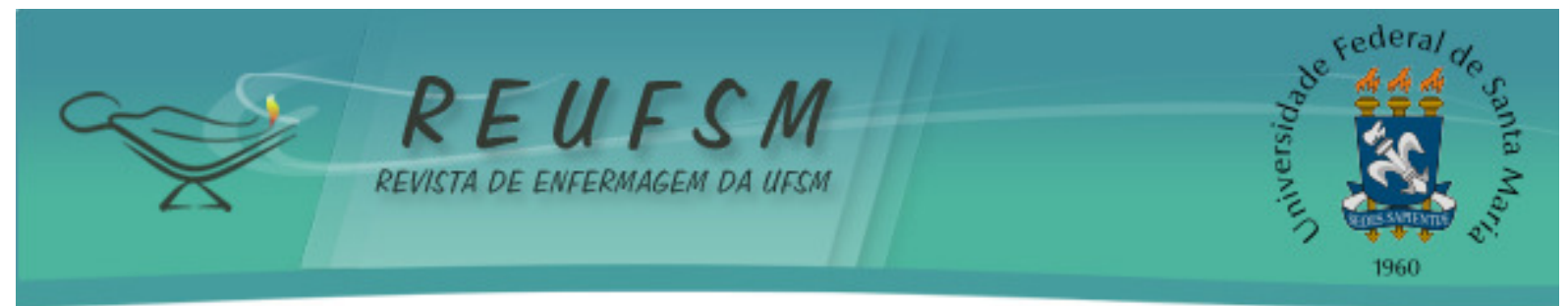

estariam livres das infecções; enquanto outros familiares esperavam que ocorresse a melhora da imunidade da criança, tornando o tratamento mais eficaz. Muitos relataram sobre a restrição das visitas, no qual o visitante doente poderia disseminar alguma infecção, como mostram os relatos:

[...] para diminuir a exposição às bactérias, devido a imunidade baixa. (F3)

\section{[...] para tornar o tratamento da leucemia mais eficaz. (F2)}

Fica clara a preocupação do familiar direcionada para o cuidado da criança com imunidade baixa com finalidade de trazer benefícios a saúde da criança. Em estudo realizado no serviço de Oncologia da Universidade Federal de São Paulo com cuidadores de crianças com câncer, foi observada a necessidade de direcionar informações básicas sobre o tratamento e suas peculiaridades aos cuidadores, com a proposta de proporcionar um melhor entendimento a respeito do conteúdo. ${ }^{13}$

\section{Cuidados no Isolamento Protetor: é preciso que todos tenham informações}

Ao responderem sobre seu conhecimento a respeito dos cuidados necessários à criança no isolamento protetor; alguns participantes enumeraram determinados cuidados com a criança, enquanto outros perguntaram sobre situações a respeito do banho, visitas e a atividade do brincar com outras crianças. Contudo notou-se que haviam aqueles que desconheciam totalmente sobre a temática, sendo que para alguns familiares os cuidados necessários à uma criança em isolamento protetor são a higiene e o vestuário, podendo-se observar esse aspecto nas seguintes falas:

[...] tem que ter cuidado com a higiene, tem que higienizar a mão com álcool, lavar as mãos, colocar a touca, a luva, a roupa para não entrar com bactérias e outras coisas. (F2)

[...] eu como acompanhante tenho que estar sempre de máscara, mãos sempre limpas, o local tem que estar sempre bem limpo, não pode haver fralda suja no chão ou próximo, não pode haver sujeira no local [...] (F3)

Os familiares, no entanto, nem sempre foram informados sobre tais cuidados desde o início da internação no isolamento protetor, contudo mostraram-se dispostos a aprender sobre o assunto, e quanto a utilização de um material educativo sobre as informações, acataram a ideia de obter essa ferramenta.

[...] não sei dos cuidados mínimos, não fui informada. Mas preciso saber o que pode e o que não pode para ajudar meu filho. Porque só tem eu para cuidar dele. (F1)

[...] seria ótimo e necessário um material assim. Uma forma prática e rápida que a gente que não tem experiência, para aprender sobre as práticas e cuidados no isolamento. (F8) 


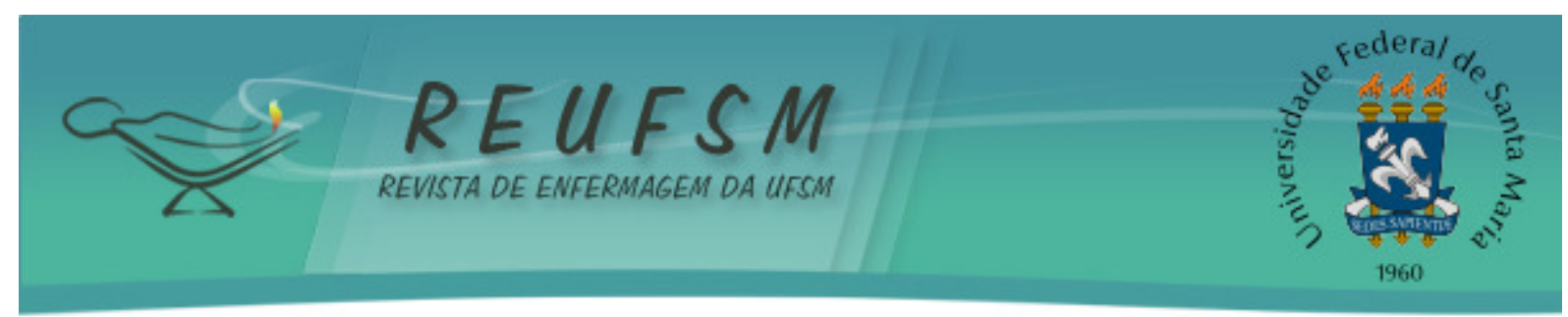

Destaca-se no perfil dos participantes, a figura da mãe como ser representativo no acompanhamento de crianças internadas. Em estudo realizado na região Nordeste em uma instituição pública de atendimento pediátrico observou-se, no cotidiano hospitalar, que a mãe permanece ao lado da criança durante a hospitalização. Isso se torna frequente visto que, em grande parte dos cuidados destinados aos filhos, ela assume essa atividade principal que se estende ao ambiente hospitalar. ${ }^{14}$

Observa-se que, na maioria das vezes, a mãe prioriza o cuidado da criança doente. Esse fato corrobora com o estudo similar realizado em uma unidade hospitalar de Goiânia, no qual as mães que possuem filhos enfermos, demonstraram preferência em permanecer ao lado da criança, durante o período de internação. Elas consideram que em casa, longe do filho doente, aumentam as preocupações sobre o estado geral da criança, no que diz respeito aos cuidados em relação as atividades diárias que inclui: comer, vestir, dormir, além da ansiedade pela melhora do quadro clínico da criança para possível alta para o domicílio. $^{15}$

Em outras situações, o pai exerce o papel fundamental para dar suporte a criança doente, pois a mulher exerce funções importantes no cuidado de outros membros da família. Alguns autores ${ }^{16}$ consideram que a inconstância do vínculo empregatício dos pais e a presença de filhos menores tornam as mães mais ausentes do processo do cuidar durante a hospitalização de um de seus filhos, e esses são uns dos fatores que vem colaborando para a permanência do pai-acompanhante no ambiente hospitalar pediátrico.

Independentemente de quem participa do processo do cuidar, seja o pai, ou a mãe, é importante que o familiar esteja disposto a compartilhar dessa experiência para que possa ser vivida de forma a não causar traumas ou sequelas na vida da criança. Em diversas situações, o familiar pode vivenciar experiências negativas em função da quebra na estrutura familiar, da redução da autonomia dos cuidados em relação à criança no ambiente hospitalar. Essas situações contribuem para o sentimento de fragilidade do acompanhante que necessita estar ativo e participativo no cuidar o filho doente. ${ }^{17}$

Observou-se, no estudo, que os familiares possuem a faixa etária entre 20 e 45 anos, ou seja, vida profissional ativa, entretanto muitos não tinham atividade profissional. Tal situação reflete a dificuldade que os pais possuem em dividir seu tempo entre o cuidado da criança doente e a profissão. Familiares que prestam assistência a seus filhos dia e noite, aliado ao fato de não ter com quem dividir o cuidado do paciente, pode contribuir para a perda de emprego dos cuidadores. ${ }^{15}$

Constatou-se que mais da metade dos participantes não possuíam o ensino médio completo e outros tinham apenas o ensino fundamental, mas mostraram-se dispostos em aprender as práticas que direcionam ao cuidado do filho, a partir de informações adquiridas ao longo da hospitalização para o tratamento da criança com LLA. Nesse sentido, a orientação adequada aos familiares sobre a doença, suas expectativas referentes ao tratamento, as normas e rotinas hospitalares agregaram conhecimento do saber/fazer para assistir com qualidade. ${ }^{2}$

Neste estudo, notou-se que $72,7 \%$ das crianças com leucemia pertenciam ao gênero masculino, com faixa etária entre 1 a 14 anos, sendo que esses dados corroboram com os dados epidemiológicos nacionais. Pesquisas realizadas em 2016 pelo Instituto Nacional do Câncer mostram que a leucemia é o tipo de câncer infantil mais frequente no Brasil compreendendo indivíduos de 0 e 17 anos e afetando mais o gênero masculino. ${ }^{18}$

Nota-se que a faixa etária das crianças internadas é bastante diversificada. Contudo, o tratamento independe da idade, necessitando de múltiplas hospitalizações para iniciar e finalizar protocolos quimioterápicos, realizar exames complexos e de rotina, a fim de acompanhar a evolução do quadro clínico. Envolve programações de datas e horários prédeterminados para infusão dos antineoplásicos, no qual o familiar deve receber orientações 


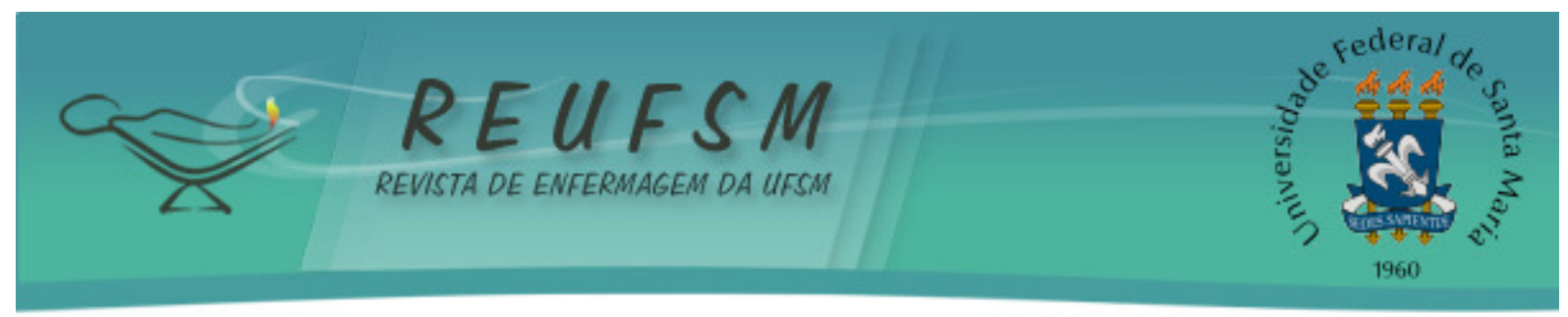

quanto aos efeitos esperados e adversos da terapia. ${ }^{19}$

A ação do medicamento quimioterápico é responsável pela imunossupressão da medula óssea, ocasionando baixa defesa orgânica nas crianças. Em estudo realizado em um hospital de oncopediatria no interior de São Paulo, todas as crianças submetidas ao tratamento com drogas antineoplásicas apresentaram diversas reações como: anemia, fadiga, leucopenia, apatia, perda do apetite, alopecia, perda de peso, diarreia, hematomas, mucosite, náuseas e vômitos. Apesar dos efeitos colaterais, a frequência dos ciclos foi mantida para o sucesso do tratamento. ${ }^{20}$

Esta condição de imunossupressão, expõe o organismo frágil da criança às bactérias nocivas e oportunistas e, nesse sentido, os familiares precisam das orientações de como lidar com a criança no isolamento protetor para auxiliar na prevenção de outras doenças. Em 2012 foi realizado um estudo comparativo de diversos centros de saúde, para observar a eficácia do isolamento protetor ou reverso, constatando-se que contribuiu de forma significativa para redução de candidíase e infecções por gram-positivos. ${ }^{21}$ No entanto, para que o cuidado com a criança em isolamento protetor seja eficaz, os familiares precisam conhecer as ações específicas a serem praticadas e os profissionais devem oferecer esse conhecimento peculiar sendo que, para isso, a comunicação é a ferramenta mais utilizada. Nesse sentido, são necessários profissionais com competência para educar e orientar de forma apropriada a família, a fim de colaborar na assistência, recuperação e na prevenção das complicações da criança enferma. ${ }^{2}$

Sabe-se que educar não é papel exclusivo da equipe de Enfermagem. Nesta instituição onde foi realizada a pesquisa, a equipe multiprofissional conta com médicos, enfermeiros, assistente social, psicólogo, odontólogo e técnicos de enfermagem para educar e assistir a todos os pacientes de forma igualitária, dentro das suas competências. Estes profissionais são capacitados para cuidar, orientar e informar o familiar sobre os cuidados com o paciente internado. ${ }^{22}$

A orientação realizada de maneira eficaz, pode gerar mudanças no comportamento, agregando saberes para a prática cotidiana. Pesquisa realizada na maternidade pública de Fortaleza, revelou que as mães que receberam orientações quanto ao cuidado de recémnascidos em unidade de terapia intensiva neonatal, conseguiram colaborar com a assistência no método canguru, promovendo a recuperação da criança em menor tempo, com consequente alta hospitalar. Nesse estudo, os familiares relataram que as orientações foram fundamentais para aprender a lidar com a criança no hospital e no domicílio. ${ }^{23}$

De modo geral, a orientação para os familiares refere-se aos cuidados mínimos a serem realizados com a criança com baixa imunidade no isolamento protetor, estando direcionados a prevenção de situações que podem desencadear uma complicação de origem exógena, destacando-se a aglomeração de pessoas que podem estar com doenças infectocontagiosas, o acúmulo de alimentos no isolamento, o que predispõe a proliferação de bactérias e exposição da criança a ambientes insalubres, visto que a ação da quimioterapia os deixa mais vulneráveis as infecções. ${ }^{23}$

Dentre esses cuidados, os familiares relataram a importância do uso de equipamentos de proteção individual (EPI) para minimizar os riscos de contaminação, e citaram como exemplo, a máscara e o gorro. Em relação a utilização de procedimentos padrão, mencionaram a lavagem das mãos, limpeza do ambiente, uso de álcool-gel a 70\%, restrição de visitas, a higiene pessoal e a proibição da saída da criança do isolamento protetor, de modo a não transitar nas enfermarias ou nos corredores da instituição. Essas práticas vivenciadas por alguns colaboradores corroboram com cuidados descritos pela Anvisa, que incluem lavagem das mãos, uso do álcool-gel a $70 \%$ e restrição de visitas. ${ }^{21}$

O conhecimento dos familiares sobre os cuidados com crianças em isolamento protetor, está pautado em orientações direcionadas por profissionais que conhecem a 


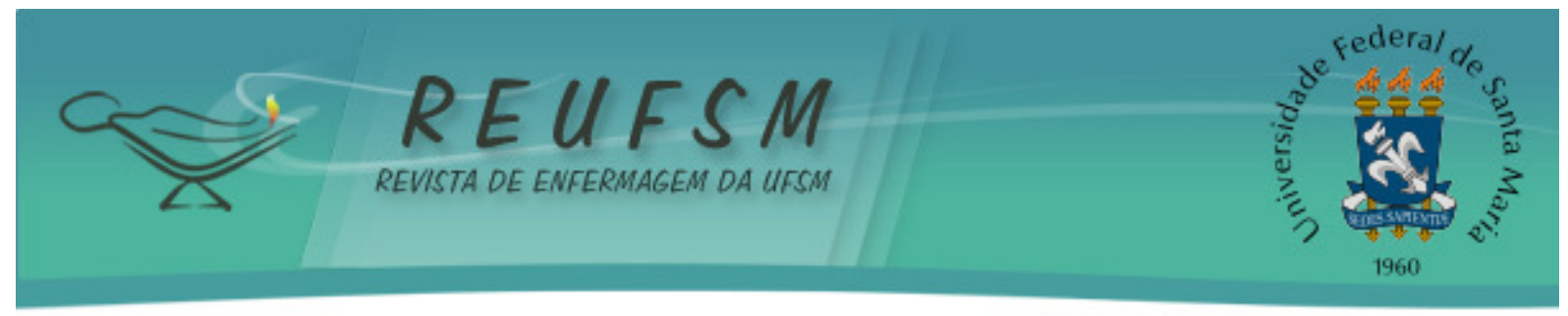

rotina da instituição, pais que experienciaram a vivência desse novo ambiente e transmitem esses cuidados de forma mais acessível a outros familiares. Além disso, muitos familiares relataram a necessidade de uma orientação mais concreta a partir de um material educativo, sobre o isolamento protetor para manusear quando surgisse a dúvida. Vale ressaltar que essas tecnologias educativas são ferramentas valiosas para educar, orientar e treinar um determinado público sobre um tema específico. ${ }^{24}$

Constatou-se nas falas dos participantes que a intenção do material educativo sobre o isolamento protetor seria a forma mais adequada para otimizar e transmitir as informações. A finalidade dessas tecnologias educacionais é colaborar nas atividades de ensino-aprendizagem, mediando práticas educacionais com tipos específicos de usuários. Revela-se o interesse dos familiares em aprender para assistir a criança com leucemia de maneira apropriada. ${ }^{25}$

\section{CONSIDERAÇÕES FINAIS}

Procurou-se, nesta pesquisa, descrever o conhecimento dos familiares de crianças diagnosticadas com LLA, a respeito do isolamento protetor, envolvendo os cuidados e as orientações necessários para crianças com imunidade baixa, durante a hospitalização. A partir disso, foi observado que o conhecimento dos familiares sobre a rotina e os cuidados à criança em isolamento é limitado e insuficiente.

Alguns familiares encontraram dificuldade em responder as perguntas por não conhecer o serviço e/ou não obter informações dentro da instituição para tal atividade. Notou-se que orientações fornecidas por parte de alguns profissionais, muitas vezes foram incompreensíveis aos familiares. Para alcançar uma comunicação eficaz, é necessário buscar o conhecimento que envolve o familiar-paciente-meio ambiente que está inserido, trabalhando nas fragilidades sobre o conteúdo proposto e tornando-os coparticipantes do cuidado.

Sugeriram a concepção de um material educativo contendo informações inerentes ao assunto para facilitar a aprendizagem direcionada ao cuidado da criança em isolamento. As limitações deste estudo abrangeram familiares de outras culturas (indígenas) pela dificuldade de compreender a língua portuguesa.

A pesquisa contribui para que enfermeiros que coordenam os serviços assistenciais de saúde, possam refletir sobre a educação em saúde oferecida aos usuários, fazendo do ensino-aprendizagem uma ferramenta essencial para o empoderamento da família quanto ao cuidado peculiar e humanizado de crianças com baixa imunidade.

\section{REFERÊNCIAS}

1. Santana JCB, Caldeira CLG, Martins FPL, Andrade JD, Silva CCD. Vivências do cuidar de pacientes na terminalidade da vida: percepção de um grupo de acadêmicos de enfermagem. Rev Enferm Revista. 2015;18(2):29-41.

2. Brasil. Ministério da Saúde. Instituto Nacional do Câncer. Incidência do Câncer no Brasil. Rio de Janeiro: INCA; 2014.

3. Sales CA, Santos GM, Santos JA, Marcon SS. O impacto do diagnóstico do câncer infantil no ambiente familiar e o cuidado recebido. Rev Eletronica Enferm [Internet]. 2012 [acesso em 2016 dez 8];14(4):841-9. Disponível em: www.fen.ufg.br /fen_revista/v14/n4/pdf/v14n4a12.pdf.

4. Dantas GKS, Silva LTA, Passos XS, Carneiro CC. Diagnóstico diferencial da leucemia linfóide aguda em pacientes infanto juvenis. Rev Universidade Vale do Rio Verde [Internet]. 2015 [acesso em 2016 nov 3];13(2):3-18. Disponível em: 


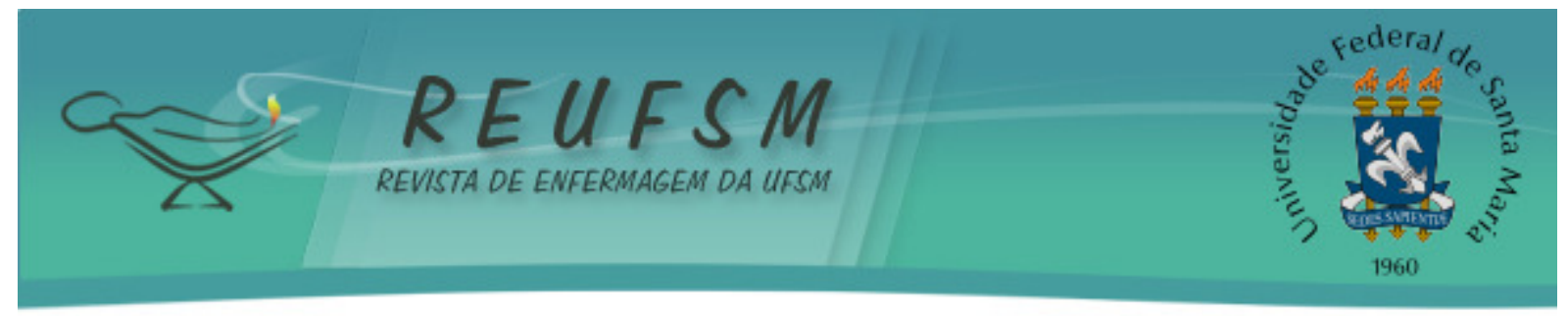

www.scielo.br/scielo.php?script=sci_arttext\&pid=S1519-38292002000100010.

5. Viero V, Beck CLC, Freitas PHF, Coelho APF, Lima SBS, Machado BP. Enfrentamentos da criança com câncer frente ao afastamento escolar devido internação hospitalar. Rev Enferm UFSM. $2014 \mathrm{abr} /$ jun [acesso 2016 out 13];4(2):368-377. Disponível em: https://periodicos.ufsm.br/reufsm/article/download/10956/pdf.

6. Reichert APS, Vasconcelos GLV, Eickmann SH, Lima MC. Avaliação da Implementação de uma intervenção educativa em vigilância do desenvolvimento infantil com os enfermeiros. Rev Escola Enferm USP. 2012;46(5):1049-56.

7. Bellesso M. Febrile neutropenia studies in Brazil: treatment and cost management based on analyses of cases. Rev Bras Hematol Hemoter [Internet]. 2013 [acesso em 2016 jan 19];35(1):3-4. Disponível em: http://www.scielo.br/pdf/rbhh/v35n1/v35n1a02.pdf.

8. Souza TV, Oliveira ICS. Interação familiar/acompanhante e equipe de enfermagem no cuidado à criança hospitalizada: perspectivas para a enfermagem pediátrica. Esc Anna Nery Rio de Janeiro. 2010;14(3):551-9.

9. Moreira APA, Sabóia VM, Camacho ACLF, Daher DV, Teixeira E. Jogo educativo de administração de medicamentos: um estudo de validação. Rev Bras Enferm. 2014;67(4):528-34.

10. Siqueira HBOM, Pelegrin AKAP, Gomez RRF, Silva TCR, Sousa FAEF. Percepção de adolescentes com câncer: pesquisa fenomenológica. Rev Abordagem Gestál [Internet]. 2015 [acesso em 2016 mar 8];21(1):13-21. Disponível em: http://pepsic.bvsalud.org/pdf/rag/v21n1/v21n1a03.pdf.

11. Ferreira NV, Pereira IDAF. O desafio do conhecimento: pesquisa qualitativa em saúde. J Manag Prim Health Care. 2014;5(2):258-61.

12. Araújo YB, Reichert APS, Vasconcelos MGL, Collet N. Fragilidade da rede social de famílias de crianças com doença crônica. Rev Bras Enferm [Internet]. 2013 [acesso em 2016 nov 25];66(5):675-81. Disponível em: https://dx.doi.org/10.1590/S003471672013000500006 .

13. Rubira EA, Marcon SR, Belasco AGS, Gaíva MAM, Espinosa MM. Sobrecarga e qualidade de vida de cuidadores de criança e adolescentes com câncer em tratamento quimioterápico. Acta Paul Enferm. 2012;25(4):567-73.

14. Silva TP, Silva MM, Valadares GV, Silva ÍR, Leite JL. Gerenciamento do cuidado de enfermagem à criança em condição crônica hospitalizada. Rev Bras Enferm [Internet]. 2015 [acesso em 2016 dez 8];68(4):641-8. Disponível em: http://dx.doi.org/10.1590/00347167.2015680410i.

15. Gomes GC, Oliveira PK. Vivências da familia no hospital durante a internação da criança. Rev Gaúcha Enferm [Internet]. 2012 [acesso 2016 jun 17];33(4):165-71. Available from: http://http://dx.doi.org/10.1590/S1983-14472012000400021.

16. Soares JDAD, Brito RS, Carvalho JBL. A presença do pai/acompanhante no âmbito hospitalar: revisão integrativa. Rev enferm UFPE [Internet]. 2014 [acesso em 2016 mar 8];8(7):2095-106. Disponível em: http://www.revista.ufpe.br/revistaenfermagem/index.php/revista/article/view/6022/pdf _5536.

17. Santos LF, Oliveira LMAC, Barbosa MA, Siqueira KM, Peixoto MKAV. Reflexos da hospitalização da criança na vida do familiar acompanhante. Rev Bras Enferm. 


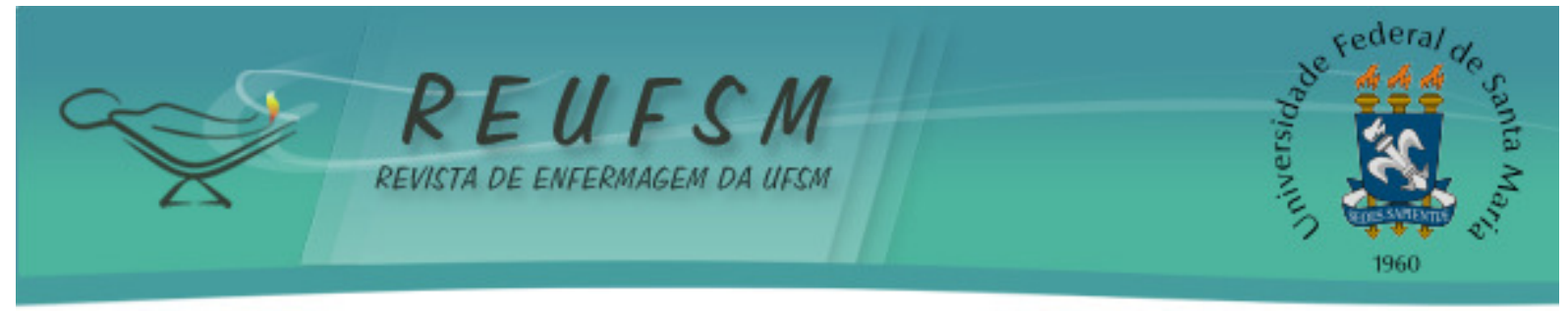

2013;66(4):473-8.

18. Nehmy RMQ, Brito AC, Mota JAC, Oliveira BM. A perspectiva dos pais sobre a obtenção do diagnóstico de leucemia linfóide aguda em crianças e adolescentes: uma experiência no Brasil. Rev Bras Saude Mater Infant. 2011 [acesso em 2016 dez 16];11(3):293-9. Disponível em: $\quad$ http: //www.scielo.br/scielo. php?script=sci_arttext\&pd=S1519$38292011000300010 \&$ lng=en.http://dx.doi.org /10.1590/S1519-38292011000300010.

19. Cicogna EC, Nascimento LC, Lima RAG. Crianças e adolescentes com câncer: experiências com a quimioterapia. Rev Latinoam Enferm. 2010 [acesso em dez 11];18(5):[9 telas]. Disponível em: http://www.scielo.br/pdf/rlae/v18n5/pt_05.pdf.

20. Garbin LM, Silveira RCCP, Braga FTMM, Carvalho EC. Medidas utilizadas na prevenção de infecções em transplante de célulastronco hematopoéticas: evidências para a prática. Rev Latinoam Enferm. 2011;19(3):640-50.

21. Bifulco VA. Psico-oncologia: apoio emocional para o criança, a família e a equipe no enfrentamento ao câncer. In: Bifulco VA, Fernandes Jr HJ, organizadores. Câncer: uma visão multiprofissional. Barueri: Minha Editora; 2010.

22. Amador DD, Gomes IP, Reichert APS, Collet N. Repercussões do câncer infantil para o cuidador familiar: revisão integrativa. Rev Bras Enferm [Internet]. 2013 [acesso em 2016 maio 8];;66(2):267-70. Disponível em: http://www.scielo.br/pdf/reben/v66n2/17.pdf.

23. Nunes NP, Pessoa UML, Mont'Alverne DGB, Sá FE, Carvalho EM. Método canguru: percepção materna acerca da vivência na unidade de terapia intensiva neonatal. Rev Bras Promoç Saúde. 2015;28(3):387-93.

24. Teixeira E; Mota VMSS. Tecnologias educacionais em foco. São Caetano do Sul (SP): Difusão Editora; 2011. (Educação em saúde; 2).

25. Assunção APF, Barbosa CR, Teixeira E, Medeiros HP, Tavares IC, Sabóia VM. Práticas e tecnologias educacionais no cotidiano de enfermeiras da estratégia saúde da família. Rev Enferm UFPE [Internet]. 2013[acesso em dez 8];7(11):6329-35. Disponível em: https://periodicos.ufpe.br/revistas/ revistaenfermagem/article/download/12276/14927.

Data de recebimento: 05/07/2016

Data de aceite: 15/05/2017

Autor correspondente: Ellen Pessoa Rocha

Endereço postal: Rua Ayrão, $n^{\circ}$ 2239, bairro: Praça 14 de Janeiro. Cep 69025-050. Manaus, Amazonas, Brasil. Fone: 92 99466-6998. Email: rocha.ellen2011@hotmail.com 